\title{
Cultivation of Cross-cultural Awareness in English Teaching in Military Academies
}

\author{
Yanjuan Zhang \\ Department of Foreign Language Teaching and Research \\ Army Academy of Artillery and Air Defense \\ Hefei, China
}

\author{
Lan $\mathrm{Hu}$ \\ Department of Foreign Language Teaching and Research \\ Army Academy of Artillery and Air Defense \\ Hefei, China
}

\begin{abstract}
With the rapid development of technology and society, the main stream of world development is the globalization. The communication among people from different cultures has become more and more frequent. So every field is in desperate need of people who are familiar with foreign cultures and capable of communicating accurately and appropriately in cross-cultural situations. The army is no exception. It needs lots of foreign language talents who have the cross-cultural awareness and intercultural communicative competence. However, the situation of culture teaching in most military academies is unsatisfied and many cadets lack crosscultural awareness. In this paper, the author puts forward some suggestions on the cultivation of cross-cultural awareness of cadets.
\end{abstract}

Keywords-cultivation; cross-cultural awareness; English teaching; military academies

\section{INTRODUCTION}

Cross-cultural awareness is the ability to understand cultures - your own and others - by means of objective, nonjudgmental comparisons. It is an appreciation and an understanding of cultural pluralism - the ability to get rid of our ethnocentric tendencies and to accept another culture on its own terms.

Hanvey (1979) thinks that there are four levels of crosscultural awareness. At the first level, one only notices some apparent cultural features. At the second level, one may have already noticed some significant cultural features of foreign culture which have obvious differences from those of their own mother culture. At this time, cultural conflicts may often occur. At the third level, one may be able to have a theoretical or reasonable understanding of the foreign cultural feature which is obviously different from those of their own culture. The fourth level is the goal that is the most difficult to achieve. At this level, one may consider about the opposite side by putting oneself in the same position and have a real understanding of what the opposite side has been doing. This level can be attained only after long-term life experience.

Developing cross-cultural awareness usually goes along with learning a new language and gets exposed to a new culture. Becoming more aware of the influence of cultural values has many positive consequences. It leads to better understanding of us and of others. We become more tolerant and less defensive, and we can enjoy the cultural difference and understand the foreign language better.

During the process of foreign language teaching, teachers should focus on cultivating students' cross-cultural awareness. Just like learning a language, the development of cross-cultural awareness is a process. It does not occur all at once, like switching on a light. It starts at the stage of no understanding and moves to the stage of true empathy and cultural respect. Generally speaking, the development of cross-cultural awareness can be divided into five stages. (Zhuang Enping, 2009) Stage One: No Understanding, Stage Two: Superficial Understanding, Stage Three: Growing Understanding and Possible Conflict, Stage Four: Greater Intellectual Understanding, Stage Five: True Empathy and Cultural Respect.

All in all, although the experts abroad and at home have done lots of researches on culture teaching and intercultural area, the problem still exists. They consider culture teaching as a special phenomenon to explore, it has a theoretical guidance, but in the process of education, they didn't provide a specific model on how to carry out culture teaching. That is to say, there is a lack of connection between the theory and practice, so it is difficult to use the theory to guide practice. Thus, this paper intends to discuss how to cultivate cadets' cross-cultural awareness in practice.

\section{Suggestions on Cultivating CAdets' CROSS- CULTURAL AWARENESS}

At present, language teaching and culture teaching in military academies are still isolated from each other. Language teaching is carried out unconcerned with the context of culture. Thus, the cadets' language study is to a great extent hindered without proper understanding of the cultural background of the language forms. Therefore, the current teaching situation in military academies is neither helpful in enhancing cadets' language proficiency, nor can it benefit the cultivation of cadets' cross-cultural awareness. In order to improve cadets' cultural awareness, it is urgent to conduct culture teaching in military academies. The author tries to put forward some suggestions on how to integrate culture teaching into English education effectively and cultivate cadets' cross-cultural awareness in military academies. First of all, we should pay much attention to some crucial factors: syllabus, evaluation system and 
textbooks. All these factors function as prerequisites of integrating culture teaching into English learning. Next, some useful techniques of culture teaching can be applied in English courses. The author will address these issues respectively.

\section{A. Prerequisites of Integrating Culture Teaching into English Teaching}

In order to guarantee the successful integration of culture teaching into English education, the author suggests: (1) the syllabus for English learning should be revised from the perspective of culture teaching; (2) the current evaluation system should be optimized; (3) the culture-loaded textbooks should be compiled.

1) Revising the current syllabus: According to F. Dubin \& E. Olshtain (2002), a syllabus is a more detailed and operational statement of teaching and learning elements which translates the philosophy of the curriculum into a series of planned steps leading towards more narrowly defined objectives at each level. Once a syllabus is designed, all the elements, such as the content and the objectives of the instruction, the time arranged for it, the techniques used, the assessment and evaluation and the like are specified to guide the implementation of teaching. So, a systematic cultural syllabus is vital for the successful implementation of culture teaching in English education. English education should aim not only to improve students' linguistic proficiency for academic study but also to help them foster cultural awareness and sensitivity to foreign cultures, thus enhancing their all-around cultural quality. In short, the syllabus should be designed to achieve the dual purpose of improving linguistic competence and cross-cultural competence simultaneously.

2) Reforming the evaluation system: Based on the author's experience in teaching, we find in most military academies, the examinations, especially, CET4 and CET6 are the guidance of the English teaching. They decide how teachers teach and how students learn. Although English examination system nowadays is undergoing reforms, its main concern is still on measuring cadets' language proficiency level, ignoring the cultivation of cross-cultural awareness of cadets. In order to encourage teachers and cadets to notice the development of cross-cultural awareness, we must reform the evaluation system, including the form and content of English test. First, the college English test should include not only the test of cadets' language knowledge but also the test of cadets' cultural knowledge and cross-cultural awareness. Second, the content of test should be enlarged, such as psychological culture, communicative strategies, non-verbal communication, etc.

3) Refining textbooks: Generally speaking, for the learning of the target language and culture, textbooks are the most important input. Especially in the military academies, owing to their special environment, the source of acquiring cultural knowledge is very limited for cadets. For the majority of the English teachers in military academies, they present cultural information or knowledge through the medium of textbooks. To the disappointment of teachers and cadets, the textbooks available in China are not satisfactory. On one hand, textbooks are not practical and convenient to conduct activities concerning culture, and can't offer enough cultural background and teaching learning activities for teachers. On the other hand, the materials for reading and speaking practice are outdated, and can't heighten learners' motivation of learning, which surely affects the outcome of learning. As a result, in order to develop learners' cross-cultural awareness, traditional textbooks need to be refined. Experts who compile books should attach importance to the integration of language and culture.

\section{B. Incorporating Culture Teaching into English Teaching in Military Academies}

1) Basic principles of culture teaching: In the process of foreign language teaching, in order to help students improve cross-cultural awareness and cross-cultural competence, English teachers should follow some basic principles of culture teaching. The author suggests that English teachers should adhere to the following three principles:

a) Principle of practicality: This principle requires that during the process of culture teaching, cultural content and language content should be connected with each other closely according to students' actual daily life, only by doing this can students learn something useful and get something in the learning. (Shu Dingfang, 1996: 144) In this way, students will feel that the relation between language and culture is not abstract and bored. On the other hand, the close connection between culture learning and language communicative practice could arouse students' interest in learning language and culture and enhance the teaching efficiency. Therefore, as language teachers, in teaching language, we should introduce the related cultural information from the practical point of teaching. In military academies, every cadet is familiar with the knowledge about military rank. Teachers can introduce some knowledge about it. For instance, military rank of America, Britain and China do not match one by one. By explaining their differences, our cadets will not be confused. It's quite useful in their daily life. It's practical.

b) Principle of stage: Language teaching should be conducted in an orderly way, and so should culture teaching. In doing culture teaching, English teachers should consider students' age, cognitive ability, psychological conditions and language level. This was called the principle of stage. Culture teaching was divided into three stages by Hammedy: preliminary, secondary and advanced. The preliminary stage is the cultivation of interest in the culture; the secondary stage is to understand cultural differences and study cultural regulations; the advanced stage is to train the synthetic concept and their ability in doing research on culture. In the language classroom, the cultural content should be covered gradually, from the surface level to deeper level, from the 
simple to the complex. In addition, students should be classified into several groups according to their English proficiency. For students with low English proficiency, English teachers could first help them understand the cultural information in the textbook or else they will lose interest in cultural knowledge. With the increase of students' cultural knowledge and the improvement of their language skills, the content of culture teaching should go in depth. For students with higher English proficiency, more cultural information, including the target culture and the culture of other English-speaking countries, can be introduced. Besides, teachers could encourage them to use critical thinking to analyze cross-cultural phenomena in our life.

c) Principle of appropriateness: In the process of integrating culture into language teaching, English teachers should keep the principle of appropriateness in mind. This principle includes the appropriateness both in the teaching contents and teaching methods. As far as the content of culture teaching is concerned, teachers should handle the relationship between the main-stream culture and the subculture, the diachronic culture and the synchronic culture appropriately in the practice of culture teaching. For the main-stream culture, teachers should elaborate and practice it again and again. Meanwhile, in the teaching, the relationship between diachronism and synchronism in the cultural content should be dealt with properly. The focus should be placed on synchronic culture with a moderate introduction of diachronic content, only in this way can students understand the source of some cultural customs and traditions better. As far as the methods of culture teaching are concerned, the relationship between teachers' instruction and students' self-study should be coordinated. Teachers' instruction of cultural knowledge should be selective and focused, and students should be encouraged to acquire the cultural knowledge by reading and listening more after class. Teachers should be the organizer and guider of students' extracurricular culture learning.

\section{2) Methods of culture teaching}

a) Comparison: In culture teaching, comparison is a most important method. People who grow up in a certain cultural environment are usually influenced by a specific culture, so people from different cultures will encounter communication failures more or less in interaction with each other. Due to the lack of the understanding about cultural differences, some cultural phenomena we are accustomed to may turn out to be hard for people from a different culture to understand. Therefore, foreign language learners should make comparisons between different cultures so as to know their similarities and differences. Only by comparison can we get a deeper understanding of the target culture and gain the cultural sensitivity in cross-cultural communication.

b) Integration: The inseparability of language and culture makes us realize that culture teaching cannot be completely isolated from language teaching. To achieve the goal of cultivating students' cross-cultural awareness, culture teaching should be systematically integrated into language teaching. On the one hand, language learning is the means of culture learning. On the other hand, culture learning provides rich and authentic materials for language learning, which ensures the cultivation of cross-cultural awareness. Specifically, integration is a teaching method which combines the cultural content with the language material. This method itself can arouse the students' interest, at the same time, the learning of cultural knowledge and language knowledge may influence students unconsciously. In a word, the principle of integration should be followed by English teachers in both teaching practice and classroom assessment.

3) The strategies of culture teaching in the classroom: In military academies, the high degree of unity in management restricts the cadets from bringing their individuality into full play. As a result, most cadets would behave in the same way as others, and no one would like to act differently from other cadets in class. Some teachers tend to dominate the class too much. In class, the cadets are apt to listen a lot, but speak very little; they are inclined to memorize a great deal, but participate very little; there are almost no communication between cadets; the classes are very likely to degenerate into a one-man show of the teacher. This situation prevents the development of cadets' crosscultural awareness. Therefore, in language teaching, teachers should go to great lengths to create comfortable classroom environment for cadets so that they can speak out actively. They should become the designers and organizers of communication activities and encourage cadets to participate in all kinds of cultural activities to develop their cross-cultural awareness. In the language class of military academies, we can resort to the following activities, which could help the cadets to understand culture better.

a) Role-play: Role-play is one of the instructional techniques of social-cultural strategy training. By role-play, the learners' communicative competence can be improved. In college English class, teachers can use role-play in postreading stage to deepen students' understanding of the text, stimulate their interest in learning and using English and improve their communicative fluency. For example, when we learn the text "The Sampler" in college English book one, we can ask students to assume certain roles in the certain situation. One plays the sampler, and the other plays the shop assistant to practice the contextual dialogue.

b) Learning about culture through literature reading: Literature reflects society's view, values and beliefs, which is a good way to open up a door to a whole new world where you can be exposed to many facets of the target culture. Literature is one of many tools used to discuss culture with students and many literary works are actually utilized for language teaching. Kramsch (1993: 130) says that a piece of literary text appeals to the students' emotions, stays in their memories, and seizes their interest. Through literature, students may attain a deeper understanding of the target culture, and this also results in better appreciation of 
literature. As English teachers in military academies, we should encourage cadets to read literature, such as fiction, poems, children's tales, folk tales, etc. For those literature works which are difficult for students to understand, teachers can read a little bit for each class, and explain what the authors have written. In this way the cultivation of students' cultural awareness can be made more efficient.

c) Lectures of special topics: Lectures of special topics concerning culture or cultural comparison are thought to be easily understood. Teachers in military academies should often give lectures on various topics of the target culture so as to provide cadets with basic cultural knowledge. For example, when teachers explain meanings of English proverbs and allusions, related cultural knowledge can be provided. In the sentence "'You chicken!' he cried, looking at Tom with contempt." Generally speaking, only English people like to use chicken to express one is very coward, but Chinese people often use mouse as a metaphor. Teachers can make a lecture on a comparative study of English and Chinese cultures in proverbs and allusions.

\section{CONCLUSION}

Although the author is a beginner in the field of intercultural studies, he does hope that this study will serve as a guide in culture teaching in military academies to raise cadets' cross-cultural awareness. The author also does believe that enlarging military cadets' cultural knowledge and developing their cross-cultural awareness are the urgent and important teaching job.

\section{REFERENCES}

[1] Byram, M. \& Zarate, G., eds. The Sociocultural and Intercultural Dimension of Language Learning and Teaching. Strasbourg Cedex: Council of Europe Publishing, 1997.

[2] Dubin, F. \& Olshtain E. Course Design. Shanghai: Shanghai Foreign Language Education Press, 2002.

[3] Fisiak, J., ed. Contrastive Linguistics and the Language Teacher. Oxford: Pergamon Press, 1981.

[4] Hanvey, R. G. "Cross-cultural Awareness." Toward Internationalism: Readings in Cross-cultural Communication. Eds. Luce, L. F. and E. C. Smith. Cambridge, Mass: Newbury House Publishers, 1979. 13-23.

[5] Hinkel, E., ed. Culture in second language teaching and learning. Shanghai: Shanghai Foreign Language Education Press, 2001.

[6] Kramsch, C. Context and Culture in Language Teaching. Oxford: Oxford University Press. 1993.

[7] Luo Changpei, Language and Culture. Beijing: Beijing University Press, 2009.

[8] Shu Dingfang, Zhuang Zhixiang. Modern Foreign Language Teaching-Theory, practice and Method. Shanghai: Shanghai Foreign Language Education Press, 1996.

[9] Wang Zhenya. Introducing English Language and Culture. Shi Jiazhuang: Hebei University Press, 2004.

[10] Zhuang Enping. English Reading Course for Intercultural Perspectives2. Shanghai: Shanghai Foreign Language Education Press, 2009. 